\title{
RECENT TRENDS IN HEALTH CARE SECTOR: A STUDY OF INDIAN PERSPECTIVE
}

\author{
Dr. Babita G Kataria ${ }^{1}$, Prof. A.K.Saini ${ }^{2} \&$ Dr. Sangeeta Gupta ${ }^{3}$
}

\begin{abstract}
The transition phase of healthcare sector in India is moving towards a culture of corporate sector. It requires a great transformation in terms of improvement and development of this sector. Patients' needs high attention and services; therefore, there should be increase in manpower and infrastructure facility. The conversion is impossible without education, use of technology, appropriate information and expert refining of information to convert into knowledge. In reference of use of technology these days' use of IT in health sector is giving ways to high storage, accurate, obtainable and timely information which help in decision making and quality treatment. The computerization of medical patient records, e-telemedicine, pathological reports, inventory maintenance, diagnosis, treatment and other decisions. The irresistible need requires resources for meeting shortage and makes India to reach world standards in medical sector. The stored data if evaluated properly will significantly enhance knowledge by discovering diseases patterns and fast decision for further treatment. The hospitals are moving towards more and more implementation of recent trends services, facilities, technology and equipment. The working of hospitals and other medical sector is seeing a transaction from manual to IT driven. The remote hospitals and primary health centers are connected and controlled through use of IT. Planning for implementing intelligent and smart hospitals in both public and private sectors is in pipe line. The study identifies emerging recent trends in health care sector in India.

Key Words: Health Care Sector, IT, Trends
\end{abstract}

\section{INTRODUCTION}

The healthcare sector in India is going through a transition stage where the patients are more demanding and requires best services. As part of the transition, all stakeholders are demanding better and more inclusive information on the efficiency of the healthcare system. The other stakeholders include pharmaceutical companies, employers, health insurance firms, lawyers, central or state government, NGO's, health care workers and patients. Healthcare organizations are overwhelmed with data, but truly lacking important information. There is an enormous volume of data but few tools in health sector to evaluate and so to further generate knowledge for effective medical treatments and other related services. All India Management Association in collaboration with Confederation of Indian Industries (CII) and Boston Consulting Group together in their "India's New Opportunities- 2020" proposed that transformation of healthcare sector will make it emerge as major sector which will principally contribute to augment revenues and further provide economic growth along with Education and IT service sectors. Also, the report further recommends that new openings are expected to generate 40 million employments and by the end of 2020, 200 billion growth of revenue will be there in nation (Kalia P. Rajesh, 2011). Therefore, this paper is going to study the recent trends of health care that are emerging in India.

\section{HEALTH CARE SECTOR}

Health care sector needs improvement and a system should be developed to an extent that it meets the needs of population, health care workers and other government \& non-government organizations. The health care planning is done at central and state level and the policies are implemented accordingly. Planning and implementation in any system needs financing mechanism, adequately-paid workforce, well trained manpower, maintained logistics for delivering of quality medicines along reliable and timely information for making policies and implementing decisions.

\subsection{Healthcare in India}

Predominately India have become hub of IT and IT enabled services which is handled by skilled manpower but then also India has a long way in comparison of implementation of health information technology with other countries. The computerization is limited to some clinical functions and administrative working. It is due to very less motivation of adoption of technology and system. In last years the health information technology (HIT) adoption in private sector shows good results but in government hospitals the pace is still very slow, although Indian government is trying to move hospitals in the direction to adopt HIT. The central, state and territories constitute and develop attributes of universal health care system of India. The Constitutions put conditions on every state to raise the standard of living and nutrition level to improve public health. It should be in the primary duties of state. The National Health Policy was updated in 2002 although it was endorsed

\footnotetext{
${ }^{1}$ Research Scholar,USMS, GGSIPU, Dwarka, New-Delhi,

${ }^{2}$ Professor, USMS, GGSIPU, Dwarka, New-Delhi,

${ }^{3}$ Professor, MERI, GGSIPU, Janak Puri, New Delhi
} 
in 1983 by the Parliament of India. By 2020 the Indian healthcare industry is expected to become US $\$ 280$ billion at such a rapid growing pace. India would need investments of nearly $\$ 20$ billion over the following years, to meet manpower shortages and other infrastructure resources to reach world medical services standards (Wikipedia, 2011). In the Hospitals the working environment is manual that is still grounded on paper. Presently functions like medical records management, form development, census maintaining, accounting, billing, insurance claims, patient admission, laboratory systems, radiology systems, pharmacy systems, operation theater, outdoor patient, financial matters and decision support system most of the areas are still managed manually on papers. Some of the hospitals have a vision now to implement and automate their working. But still long way to go as most of the hospitals and its staff have apprehensions and therefore avoid using IT. Major other factors include cost, unwillingness to switch, comfort level, lack of trained manpower and knowledge. If the hospitals get automated, it will really support them to meet challenges of modern health care services and have quality health delivery.

Implementation of health care information system will definitely improve maintenance and availability of medical records. It will further support the system to correspondingly transform from paper based transactions to electronic transactions. Best use of resource manpower, machinery or infrastructure by proper planning and sharing. Utilization of electronic media will help to reach at best diagnosis and treatment via consulting with specialized consultants worldwide for getting best advice. The Electronic health record (EHR), Computerized provider order entry (CPOE), Clinical decision support system (CDSS), Picture archiving and communications system (PACS), Bar coding, Radio frequency identification (RFID), Automated dispensing machines (ADMs), Electronic materials management (EMM) and Interoperability, these are some of the technologies used to track and manage hospital on going working. It is similar to enterprise resource planning systems and the concept refers to incorporate one IT system to another which leads to electronic communication among organizations (Hackbarth G M, Reischauer R D and Miller M E, 2004). The central government has declared that Integrated Disease Surveillance Project to be developed as national diseases surveillance system. Telemedicine centres to be built across India an initiative taken by Indian Space Research Organization. The Ministry of Health and Family are putting efforts to computerize information system in tertiary public hospitals. The private sectors are using and implementing established health information system through vendors like Wockhardt, Siemens and GE. The private hospitals are planning to integrate on a common platform and develop a fully computerized system (Virk P., Khan S. and Kumar V., 2007).

\section{ORGANIZATION OF HEALTH SERVICES IN INDIA}

The Ministry of Health and Family Welfare encompasses Department of Health \& Family Welfare, Department of Ayush, Department of Health Research and Department of AIDS Control. These departments are headed by a secretary to the government of India. The Urban sectors are served through Hospitals and Dispensaries while the Rural sector is served through Primary Health Centers. Many schemes worked in the country to cover the patients like ESIC, CGHS and many more ((Department of Information Technology, 2003).

Table 1 shows the number of dispensaries, hospitals, mobile health clinic and school health clinics are operational under directorate of health services in Delhi from 2005 - 2017. The trends are changing and the change is toward the up gradation and development of the nation (Bhushan K., 2017).

Table 1: Number Of Health Outlets Under Gnct Of Delhi During The Year 2016-17 And Previous Years

\begin{tabular}{|c|c|c|c|c|c|c|c|c|c|c|c|c|c|}
\hline S.No. & $\begin{array}{l}\text { Year Health } \\
\text { Outlets }\end{array}$ & $\begin{array}{l}2005- \\
06\end{array}$ & $\begin{array}{l}2006- \\
07\end{array}$ & $\begin{array}{l}2007- \\
08\end{array}$ & $\begin{array}{l}2008- \\
09\end{array}$ & $\begin{array}{l}2009- \\
10\end{array}$ & $\begin{array}{l}2010- \\
11\end{array}$ & $\begin{array}{l}2011- \\
12\end{array}$ & $\begin{array}{l}2012- \\
13\end{array}$ & $\begin{array}{l}2013- \\
14\end{array}$ & $\begin{array}{l}2014- \\
15\end{array}$ & $\begin{array}{l}2015- \\
16\end{array}$ & $\begin{array}{l}2016- \\
17\end{array}$ \\
\hline 1 & $\begin{array}{l}\text { Allopathic } \\
\text { Dispensaries }\end{array}$ & 182 & 184 & 188 & 214 & 220 & 234 & 247 & 256 & 260 & 260 & 242 & 245 \\
\hline 2 & $\begin{array}{l}\text { Mohalla } \\
\text { Clinic }\end{array}$ & - & - & - & - & - & - & - & - & - & - & 107 & 162 \\
\hline 3 & Polyclinic & & & & & & & & & & & 23 & 24 \\
\hline 4 & Hospitals & 33 & 33 & 34 & 35 & 38 & 38 & 38 & 39 & 39 & 39 & 38 & 38 \\
\hline 5 & $\begin{array}{l}\text { Mobile } \\
\text { Health Clinic }\end{array}$ & 71 & 67 & 68 & 72 & 90 & 90 & 90 & 90 & 90 & 43 & 43 & 24 \\
\hline 6 & $\begin{array}{l}\text { School } \\
\text { Health } \\
\text { Clinics/ } \\
\text { Referral } \\
\text { Centres } \\
\end{array}$ & 15 & 15 & 28 & 28 & 32 & 34 & 93 & 100 & 100 & 68 & 70 & 59 \\
\hline & Ayush & & & & & & & & & & & & \\
\hline $\mathrm{i}$ & Homoeopathy & 71 & 72 & 78 & 80 & 87 & 92 & 92 & 95 & 100 & 101 & 101 & 103 \\
\hline ii & Ayurvedic & 22 & 22 & 25 & 26 & 27 & 32 & 32 & 33 & 35 & 36 & 39 & 40 \\
\hline iii & Unani & 9 & 9 & 10 & 10 & 11 & 15 & 15 & 16 & 17 & 18 & 19 & 20 \\
\hline
\end{tabular}




\begin{tabular}{l|l|l|l|l|l|l|l|l|l|l|l|l|l|} 
iv & Total & 403 & 402 & 431 & 465 & 505 & 535 & 607 & 629 & 641 & 565 & 682 & 715 \\
\hline
\end{tabular}

Table contained the achievements and functioning of Director General of Health Services. It implicit the working and delivery of services through different network organizations like Allopathic Dispensaries, Mobile Health Dispensaries, School Health Clinics, Mohalla Clinic, Hospitals and Polyclinics. In Delhi the health care facilities are being delivered by a number of Non-Government \& Government Organizations. The trend in the table shows the rise in number. In last two years' new development in health care sector is in the form of opening of Mohalla Clinic and Poly clinic. It is all together new concept and new initiative. The people are visiting these clinics for small medical problems and if complexity then referred to hospitals. Advancement and increment in numbers of Homoeopathy, Ayurvedic, and Unani dispensaries and establishment of these departments in hospitals is also emerging trend in Indian health care sector.

\section{RECENT TRENDS IN HEALTH CARE SECTOR}

Indian public sector plays a key role in planning and regulating health care services. However, health services in public sector are multifarious with governance and regulatory failures, so there is dominance of private sector. Although there is massive scope for improving efficiency and achieving equity in the health care sector (Pandey A, Sharma K, Hasan H, Zodpey S P, 2012). In order to achieve efficiency in Indian healthcare scenario some of the recent trends are:

Salient Government Initiatives: The Government of India has taken extraordinary steps to improve the healthcare sector in the country such as 100 per cent foreign direct investment (FDI) is endorsed for health and medical services under the automatic route. The National Rural Health Mission (NHRM) had allocated US\$10.15 billion for the capacity enhancement and up gradation of healthcare amenities; in March 2010 the Government allocated an additional US\$ 1.2 billion for six forthcoming AIIMS-like organizations and up gradation of 13 existing Government Medical Colleges, (IBEF, 2011). The Government of India is supporting an initiative to build a "Medi City"in Gurgaon which is on 43 acres of land, will cost an estimated US\$ 493 million. The Medi City has providing allopathic treatment with alternative treatments, including Unani, Ayurveda and Homeopathic medicine.

Striking Employment Trend: private healthcare boom endures despite the slowdown. Over a period of 18 months, when most industries were busy with their restructuring operations, cleaning up books or optimizing their costs, Indian pharmaceutical and healthcare industry was adding manpower. The total employee base is 33,66,000 and there is a scope of adding 2,95,000 new jobs as well as rise in salary of the existing employees and new candidates in this sector (Ma Foi Management Consultants, 2010).

Rousing Opportunities: there are number of opportunities in main healthcare sector as well as in allied services to provide effective and efficient healthcare services like Medical Council of India (MCI) accepting Emergency medical service as one of the specialty, there are huge opportunities for personnel in this area especially Nurses, Paramedics, Technicians and Emergency medicine specialized doctors. Likewise Specialist medical care hospitals either with single specialty or multispecialty are also created in several tires II and tire III cities.

The other allied business are also en-cashing the boom in the healthcare sector e.g. nursing homes are growing at rate of $20 \%$, medical equipment growing at 15\%, clinical lab diagnostics growing at 30\%, imaging diagnostics growing at 30\%, other services which includes training \& education, aesthetics \& weight loss, retail pharmacy growing at pace rate $40 \%$.

\subsection{Health Insurance}

in India health insurance shows an upcoming trend. It has the potential to show top line growth, McKinsey-CII estimates the number of potential insurable lives at 315 million with a potential of Rs. 34,650 Crores in health insurance premium by 2015 (Thambala R., 2011)

\subsection{Medical Tourism}

India has become first choice as a destination for medical tourism which serves its consumers with well trained, Englishspeaking medical staff, state-of-the-art private hospitals and diagnostic conveniences, and comparatively low cost of treatment as compare to developed countries. India's medical tourism sector is expected to experience an annual growth rate of 30\%, making it a Rs. 9,500 Crores by 2015. therefore, attracting customers into India for medical tourism etc. could add \$ 6-50 billion in revenue and providing 10-48 million jobs directly and indirectly by 2020 (Abraham R., 2011).

\subsection{IT Intervention}

The intervention of information $\mathrm{te} \mathrm{chnolog} \mathrm{n}$ in health sector is an indication of transmuting the medical record to an online based cohesive medium from a paper-based manual system. The health sector is also involved and IT usage can be visualized in most of the medical service centers whether it is Autonomous Hospitals, District Hospitals, Primary Health Centers, or Private Hospitals. The government is on the track of implementing IT tools, planning for deploying training to staff and developing infrastructure. The IT intervention will bring transformation in existing health care sector which will have an impact to reduce healthcare costs and will able to improve better services (Honeywell, 2008).

Indian medical sector is continued to change its shape with the recent trends. These day's telecommunication and technology is getting used in Telemedicine. Through it health care may be delivered at distant, training can be imparted to the health care worker for remote medical assistance and many other medical services can be provided at door step. Robots are used for 
Robotic surgery initially which was looking difficult. Number of smart phone applications are developing to give Emergency care hence to handle medical emergencies. Network of ambulance and call for health care workers in emergencies are also developed and manage through these applications. 3D printing in this area is making its way out. In India doctors are using surgical models made through 3D technology to guide surgical procedure before and during the process. Diagnostic imaging device has brought a transition phase from analogue to digital and imaging. MRI, PET, advance level ultrasound suppliers are looking forward to modify and use latest technology to meet the demand of the sector. Stem cells: market in India is growing in government and private sector as well. Both the sectors are focused on research, awareness and imparting knowledge for stem cell banking (Sunny A.K., 2015).

For process improvement a system of health care is to be established. Three critical dimensions are involved for improving the system and are like systematically applying evidence to develop evidence based standardization of knowledge assets, systematically integrating data and measurement it includes to gather data with expertise through technology and develop standardize measurement and systematically changing processes and behavior it will help to standardize organizational work which will raise the path of best and consistent practice (Brown B., 2017).

In India there has been a tremendous growth in health services in terms of expenditures, investment, physical size and utilization. But there is a decline in health services and facilities provided by public sector and enhancement of private sector. The cause of decline is underfunding of health services, there is a need for better policies, increase resources and decentralization to be taken care as a high matter of importance. The State has to play a wider role to increase relative quality. The scaling of policies related to financial and non-financial resources. This is how the better and quality medical services may reach to the population by both public and private sector (Sheth H., 2014).

In India technology will act as a game changer for delivering the health care services. The technology will be majorly and on first hand will be adopted by private health care sector. The cost optimization will really enhance IT solution implementation and will become an integral part of management information system, patient care and patient management. As medical insurance sector is growing will require effective information retrieval and storage system. It will increase demand on health care providers to use technology and equip the existing infrastructure with latest equipment. The transition of health care with latest and modern technologies like wireless technologies and cloud computing. These technologies will play an important role to meet the manpower deficiency. Tele radiology, hospital information system, remote training of health care workers, telemedicine, electronic medical record keeping and advance management information system will be deployed in near future and a lot of advancement will be witnessed. For improvement of hospital efficiency automation and digitalization of different departments like billing, pharmacy, administration, patient care, finance and other areas will be done. It is really a challenge to adopt and implement technology with low budget, lack IT experts, reluctance for training, resistance for use from staff, inadequate support from vendors. These factors have to be dealt with utmost care for effective use of modified system (Sreenath A.V., 2018).

\section{CONCLUSION}

In India recent trends in healthcare sector are improving at the same time it met with number of issues and challenges. Like any other developing sector, these issues and challenges will hinder its growth. Seeing the scenario government is working and enhancing the infrastructure and equipping them with latest technology. It further supports to control and maintain the quality of services, diagnosis, timely decision and treatment. Recruitment and deploying of competent staff to use the facilities. The manpower should be timely updated on upgraded technologies which will support to provide best services. For all this the Government funds need to be expand which will further improve the medical amenities. The authorities are consecutively working on pilot projects to evaluate its productivity which will lead to generate a number of jobs which will also support other sector of the Indian economy. But in case, if not able to tackle these challenges, all opportunities will be ruined, lead to adverse and long standing implication on the economy. An association of government, public and private hospitals, media and education institutions should come forward to state emerging issues of brain drain, human resources to frame national and international norms, awakening of society, make them understand and educate people to take the benefits of recent trends.

\section{ACKNOWLEDGEMENTS}

We hereby acknowledge the previous research work done by esteemed authors. We appreciate and pay our sincere regards to the authors who had done so productive research work that further enlightened our path and we made to add some work in the same area of health care. We also wanted to pay our gratitude to almighty and to all our family members as without their endless support and motivation, we would have not able to step forward and do the research. 


\section{REFERENCES}

[1] Abraham R. (2011). Indian Healthcare Industry Trend 2011. Retrieved from http://www.harneedi.com/index.php/healthcare-articles/3210

[2] Bhushan K. (2017), Annual Report, Directorate General of Health Services Govt. of NCT of Delhi p 14 Retrieved From delhi.gov.in/wps/wcm/connect/.../Annual+report.pdf?MOD=AJPERES\&lmod...

[3] Brown B. (2017), Healthcare Payers and Providers: The Best System for Process Improvement, Retrieved from https://www.healthcatalyst.com/tophealthcare-trends-challenges

[4] Department of Information Technology (2003). Directorate of Health Services. Retrieved from http://delhigovt.nic.in/dept/health/dhs1.asp

[5] Hackbarth G. M., Reischauer R. D. and Miller M. E., (2004), Report to the congress: New Approaches in Medicare, p 160 Retrieved from http://www.medpac.gov/documents/june04_entire_report.pdf

[6] Honeywell (2008), "Intelligent Healthcare Management" Retrieved from https://www.honeywell-buildingsolutions.nl/assets/PDF/HBSHealthcare.pdf

[7] IBEF (2011). Health care. Retrieved from http://www.ibef.org/industry/healthcare.aspx

[8] Kalia P. R. (2011). India Outsourcing Industry 2011 - Focus on Healthcare vertical for Growth. Retrieved from http://itbizcharts.blogspot.in/2011/10/india-outsourcing-industry-2011-focus.html

[9] Ma Foi Management Consultants (2010). India is back on hiring - Ma Foi Employment Trends Survey. Retrieved from www.mafoirandstad.com/ourservices/consulting/mets.html

[10] Pandey A, Sharma K, Hasan H, Zodpey SP. Emerging Need for Health Policy Teaching in India. Indian J Public Health 2012 ; $56: 210-3$.

[11] Sheth H. (2014), CHANGING TRENDS IN THE HEALTHCARE SECTOR IN INDIA, Abhinav International Monthly Refereed Journal of Research in Management \& Technology, Vol. 3, Issue 9, pp 42-46.

[12] Sreenath A.V. (2018), Emerging trends in Indian healthcare - Technology to become a Core Function, Retrieved from https://www.wipro.com/blogs/sreenath-a-v/emerging-trends-in-indian-healthcare---technology-to-become-a-co/

[13] Sunny A. K. ( 2015), Emerging trends in India's health care , Retrieve from http://www.theweek.in/features/lifestyle/Emerging-trends-Indiahealthcare.html

[14] Thambala $\quad$ R. (2011). Indian Healthcare $\quad$ Industry $\quad$ Trends $\quad$ Retrieved http://blogs.siliconindia.com/RajeshThambala/Indian_Healthcare_Industry_Trends_2011-bid-R039Styl89132326.html

[15] Virk P., Khan S. and Kumar V. (2007), "India HIT Case Study”, Report Lab NBR center for health and aging Health Information Technology and Policy Lab. Retrieved from pacifichealthsummit.org/downloads/HITCaseStudies/Economy/IndiaHIT.pdf

[16] Wikipedia (2011). Health. Retrieved from http://en.wikipedia.org/wiki/Health 